\title{
Maternità e Politeismi
}

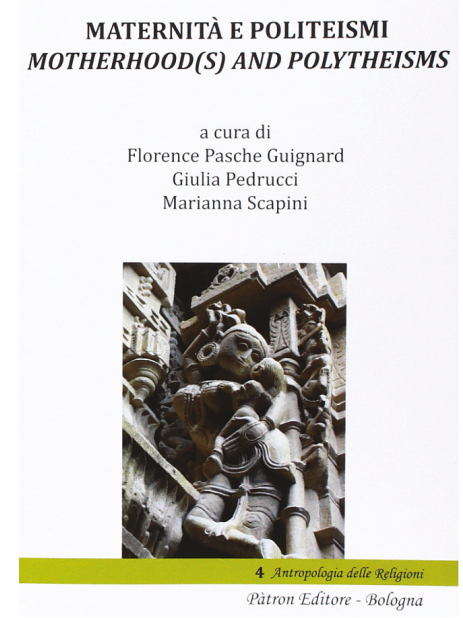

\author{
PASCHE GUIGNARD, \\ FLORENCE, PEDRUCCI, GIULIA \\ and SCAPINI, MARIANNA (eds.) \\ (2017). Maternità e Politeismi I \\ Motherhood(s) and Polytheisms. \\ Bologna: Pàtron Editore. 534 pp., \\ 48,00€ [ISBN 978-8-8555-3378-2].
}

\section{BORJA MÉNDEZ SANTIAGO \\ UNIVERSIDAD DE OVIEDO \\ MENDEZSBORJA@UNIOVI.ES}

ESTA INTERESANTE MONOGRAFÍA, QUE FUE GESTADA en gran medida durante el XXI ${ }^{\text {th }}$ IAHR World Congress, titulado The Study of Religious and Motherhood Studies: A Fruitful Interdisciplinary Potential? (Erfurt, 23-29 de agosto de 2015), pretende analizar, desde una perspectiva interdisciplinar, un tema tan importante a la hora de reconstruir la religión como las formas de ejercer la maternidad. Para lograr este objetivo de la mejor manera posible, el presente estudio trasciende el (más conocido) mundo mediterráneo, celta y nórdico para englobar otras áreas del planeta que, como Méjico, India, Japón o Nubia, resultan mucho menos conocidos, incluso para el lector especialista.

La obra, que reúne hasta 31 capítulos diferentes - articulados en cinco bloques temáticos precedidos de una sección introductoria -, no ha sido ordenada por sus editoras en función de criterios cronológicos, espaciales o lingüísticos. Así, lo que les interesaba a las mismas era, en palabras de Marianna Scapini, “(...) stimolare un dibattito su differenti 'politeismi', più o meno distanti da un punto di vista cronologico e geografico, attraverso il confronto dei rispettivi modi di concepire, sentire, 
rappresentare, idealizzare, divinizzare, mortificare, propagandare, praticare o, genericamente, vivere la maternità." Esta autora ofrece, en el primer capítulo de la obra, un resumen detallado de cada uno de los capítulos que integran la presente obra colectiva. A continuación, Giulia Pedrucci realiza un interesante recorrido historiográfico que ilustra a la perfección cómo los primeros estudiosos quisieron, inicialmente, determinar qué particular sistema de creencias (el monoteísmo o el politeísmo) surgió con anterioridad. Otros autores posteriores, como D. Sabbatucci, han propuesto que el politeísmo - que nacería en Súmer - iría propagándose por el resto del mundo. En la segunda parte de su trabajo, la autora se centra en la maternidad dentro del politeísmo griego; afirma que es conveniente distinguir entre "divinidades mayores", menos benevolentes hacia sus hijos, y "divinidades menores", que se muestran más afectuosas con relación a ellos. Florence Pasche Guignard, por su parte, se embarca en una comparación epistemológica entre los estudios que analizan la maternidad y los dedicados a la historia de las religiones, destacando tanto sus aspectos comunes como sus diferencias. Siguiendo los trabajos de Adrienne Rich, afirma que es necesario distinguir entre el término motherhood, que alude a la maternidad como institución, y la palabra mothering, que se utiliza para destacar las experiencias de las mujeres en tanto que madres. Seguidamente, la autora dedica el resto del capítulo a realizar un interesante recorrido historiográfico por todos aquellos trabajos que, independientemente de su enfoque (cronológico y/o espacial) o de la disciplina de la que parten, resultan útiles para comprender a la maternidad desde una perspectiva multifocal y que supere el tradicional acercamiento reduccionista al tema.

El primer bloque temático, titulado "Mothers in the Making: Virginity, Paideia, Fertility, Mothers and Daughters", integra cinco contribuciones. Massimo Cultraro, en su estudio, pretende arrojar cierta luz sobre la representación de la kourotrophos en época micénica. Habida cuenta los múltiples contextos en los cuales se han descubierto este tipo de representaciones, se afirma que las mismas deben responder a múltiples fines, como la protección de los niños y las niñas o como elementos propiciatorios de la maternidad y la fertilidad. Seguidamente, y tras la exposición de ciertas informaciones procedentes de los archivos micénicos de Cnossos y Pilos se analizan, en cierta profundidad, un fresco de Tirinto y un grupo escultórico de Micenas que tal vez nos permitan observar la participación de mujeres de distintas edades en ritos de iniciación de carácter femenino. A renglón seguido, Augusto Cosentino nos ofrece un estudio del culto a Perséfone en el sur de Italia. Si por una parte se analiza la presencia de Koré en unas pinakes aparecidas en el santuario de Locri Epizerifi, por otra parte constata, a través de varios ejemplos (iconográficos y epigráficos) que su figura se encuentra, en cierta medida, disociada de la de su madre Deméter. De este modo, la relación entre madre e hija, aún desvanecida, queda no obstante 
en el fondo de la narración. Concetta Giuffrè, por su parte, se centra en analizar, a través de un uso extensivo de las evidencias literarias e iconográficas, algunos de los fundamentos culturales y de los valores femeninos presentes en el culto demetríaco de la Sicilia griega. Así, afirma que las mujeres son representadas, generalmente, en momentos clave de su existencia (generalmente aquellos relacionados con el tránsito de una etapa vital a otra), y que lo que se solía buscar con ello era marcar las distintas funciones sociales realizadas por las mujeres jóvenes y mayores. A continuación, Nicoletta Petrillo estudia un corpus de matres que, aparecidas en el santuario itálico de "Fondo Patturelli" en Capua, abarcan una cronología que se extiende de la época arcaica (ss. IV-III a.C.) a los tiempos de dominación romana (ss. II-I a.C.). A través de estas imágenes observamos cómo las matres de Capua, de alguna manera, son las encargadas de supervisar las distintas fases de maduración de los más jóvenes. Además de las madres, la autora defiende que también las nodrizas podían jugar un papel importante en estos ritos. El trabajo de Federica Pitzalis sobre la maternidad en el sistema religioso etrusco cierra este primer bloque de contenidos. Mientras que, para el período más antiguo (correspondiente a la Edad del Hierro y al llamado "Orientalizante", que se extendió hasta mediados del siglo VII a.C.) disponemos solamente de hallazgos procedentes de distintas tumbas (principalmente exvotos y amuletos), para el más reciente cobran especial importancia los testimonios iconográficos (mayoritariamente en forma de estatuas) que representan a ciertas deidades como Uni-Hera, Turan-Afrodita, Vei (asociada a Deméter o a Coré) o Minerva-Atenea.

El segundo bloque de contenidos, que lleva por título "Constructing and Destroying Maternal Power" integra hasta nueve trabajos distintos que han sido, a su vez, estructurados en dos subapartados: "Political Power: Kingdoms, Lands, and Nations" (siete contribuciones) y "Magic Power: Curse and Revenge" (dos contribuciones).

La primera subsección, dedicada al "poder político", comienza con el análisis de Maria Giovanna Biga en el que se examina el culto a varias diosas sirias - Ishkhara, Tu/Nintu, Barama y Khabadu - a través de algunos textos procedentes del archivo de Ebla. Ishkhara, la deidad más honrada en Ebla, era una diosa del amor y de la noche que era especialmente venerada en palacio como protectora de las distintas fases de la vida de las mujeres. Tu/Nintu, por su parte, sería una diosa protectora del parto (lo que hablaría en favor de su conocida popularidad entre todos los estratos de población); Barama y Khabadu - paredras respectivamente de los dioses KUra y 'Àda - destacaban, por su parte, en su papel de diosas madre. Seguidamente, Marco Baldi estudia la maternidad divina en Nubia como un instrumento político de legitimación de la dinastía Kushita. Tras citar dos textos en los que se constata la asociación de la diosa con la figura de la reina madre de turno, y una vez analizadas algunas de las representaciones artísticas que nos muestran a Isis con su hijo Horus, Baldi concluye 
afirmando la enorme importancia que para los reyes nubios tenía la figura de la diosa como medio de legitimación. A renglón seguido, María Eugenia Muñoz Fernández estudia las iconografías de las diosas lactantes en el antiguo Egipto. Para ello, realiza un inventario en el que se van describiendo, cronológica y estilísticamente, las principales escenas que nos muestran amamantamientos. Si del Reino Antiguo al Nuevo predominan las imágenes del soberano siendo amamantado por nodrizas divinas, a partir del Tercer Período Intermedio estas mismas figuras tienden a dar el pecho a los dioses-niño. Fabienne Dugast, por su parte, nos presenta un estudio sobre las "Diosas madres" y las "Venus" celtas durante los primeros siglos de nuestra era. En él, analiza numerosas esculturas femeninas de época romana que han sido interpretadas, tradicionalmente, como "diosas madre" (sobre todo cuando las figuras femeninas aparecen en grupos de tres), para dar cuenta de los otros múltiples significados que las mismas pueden encerrar. El estudio de Gabriella Sciortino se centra en las figuras fenicias que nos muestran a mujeres embarazadas. Estas han aparecido, fundamentalmente, en contextos votivos o funerarios a lo largo de todo el "mundo fenicio". Pertenecientes a un período histórico determinado (desde inicios de la Edad del Hierro a la conquista persa del Levante Mediterráneo), la autora afirma que estas imágenes promueven la promoción de la maternidad en una sociedad que, aunque reconocía los peligros que implicaba la maternidad, también se caracterizaba por su afán por colonizar nuevas tierras. En su contribución, Gabriela Cursaru analiza el particular rol maternal que los griegos atribuyeron a deidades de las profundidades marinas como Doris y Tetis. La autora presenta la separación de estas diosas respecto a sus esposos (al estar relegadas en lo más profundo del océano) como absolutamente necesaria, pues la misma ayudaba "à la consolidation de la stabilité du monde, de sa structure et de son architecture" y contribuía "à produire un système cohérent et hiérarchisé de croyances (...)" (pp. 283-284). En este sentido, su fertilidad se convierte en una especie de "fuente de vida y de energía" para todas las cosas. El interesante estudio de Sucharita Sarkar, que cierra esta subsección, nos muestra una sociedad politeísta - la hindú - que se encuentra, a diferencia de las anteriores, todavía viva. En su texto aprendemos no solo cómo la escritura patriarcal hindú ha deificado tradicionalmente la maternidad, sino también la utilización, por los movimientos anticoloniales, primero, y por los anti-musulmanes, después, de la figura de la madre para simbolizar ideales determinados de "patria" que se oponen a los sostenidos por los "invasores".

La subsección titulada "Magic Power: Curse and Revenge" se inicia con el trabajo de Michaela Śmiejová Kellová acerca de la utilización del nombre de ciertas diosas-madre (como Cibeles o Deméter) en una selección de 88 defixiones procedentes del área mediterránea y que abarcan una amplia cronología (ss V. a.C. - IV d.C.). 
Más allá de las tradicionales explicaciones que aluden a la ya conocida dimensión de ultratumba de estas deidades, la autora trata de explicar las razones por las que, en el siglo II d.C. se produjo un notable incremento en el culto a las diosas-madre en buena parte de las regiones del Mediterráneo. Jessica L. Hackett analiza, por su parte, la importancia de la diosa Satuvai en las áreas rurales de Maharashtra (India). Aunque el culto a esta divinidad se limita temporalmente al parto y a la primera infancia, su naturaleza dual - en tanto que mediadora entre la vida y la muerte - le garantiza el respeto, la devoción y el temor de sus devotas. Por un lado, se trata de una figura protectora de los infantes; por otro, escribe en sus frentes su destino.

El tercer bloque de contenidos, "Maternal Thinking and Maternal Work", se compone de cinco trabajos de investigación agrupados en tres subapartados. El primero de ellos (Protection Through Preservative Love: Kourotrophic Figures) alberga, exclusivamente, un interesante trabajo en el que Giulia Pedrucci y Marianna Scapini analizan, paralelamente, las Arreforias y las Matralia. Si, por un lado, ambas sociedades atribuyen a diversas figuras femeninas humanas un importante papel en la protección de los infantes (en Atenas las nodrizas y, en Roma, las tías maternas), por el otro también otorgan, a ciertas divinidades, el papel protector de esa población infantil (Atenea y Mater Matuta, respectivamente). El segundo subapartado (Growth Through Nurturance) integra, por su parte, tres contribuciones. En la primera, Laurence Totelin destaca el rol curotrófico atribuido a unas ninfas que, por los lugares que solían habitar (ríos, saltos de agua, cuevas, mares), eran fuertemente asociadas a "lo húmedo". Partiendo de que el término griego vúupa hace alusión tanto a la joven esposa que todavía no ha dado a luz como a estas diosas de la naturaleza, no resulta difícil imaginar que, en la mentalidad griega, estas figuras ayudaran a la joven madre en los distintos pasos de la adecuación de su cuerpo a la maternidad - entre ellos, lógicamente, la generación de leche -. A continuación, Deborah Nadal parte del concepto de Śakti (potencia, fuerza, energía) dentro del hinduísmo para hablar de la diosa Kāmadhenu, la "madre-vaca", deidad que suele ser representada, la mayoría de las ocasiones, como una vaca con las ubres hinchadas que da de mamar a su ternero. Vemos, de esta manera, cómo el hinduísmo promueve una específica visión de la maternidad a través de la leche, alimento muy importante no solo en la dieta de la mayoría de los habitantes de India, sino también en su imaginario. Esta segunda subsección se cierra con el estudio de Florence Pasche Guignard sobre las figuras maternales de Devakī y Yaśodā en la poesía devocional hindú de Sūrdās, un poeta que vivió en el norte de India en el siglo XVI. La citada autora parte de la diferenciación teórica propuesta por Ruddick en Maternal Thinking: Towards a Politics of Peace (1989), entre el acto de "donner la vie" (dar la vida), "l'entretenir" (mantener, criar) y "eduquer" (educar) para ofrecer una relectura de la obra de Sūrdās que incida en 
la particular visión de este autor en torno a las relaciones maternofiliales. Así, en esta obra se refleja que la madre que cría es tanto o más importante que la madre biológica. La tercera y última subsección del bloque de contenidos (Shaping Social Acceptability (of the child) Through "Training") alberga el estudio de Arduino Maiuri sobre el rol de la mater en la religión doméstica romana. El autor, tras realizar un breve recorrido por el papel de las mujeres en el matrimonio y en la religión romanas, expone no solo cuáles eran las características que esa sociedad esperaba de las "buenas madres", sino que también reconoce la importancia que la sociedad atribuía a esas mujeres, que eran claramente consideradas esenciales a la hora de garantizar el mantenimiento del equilibrio interno de la ciuitas.

El cuarto bloque de contenidos, titulado "Good and Bad Mothers, Male Mothers, Evanescent Mothers: Negotiations and Negations of Biological Motherhood" integra cinco contribuciones muy diferentes. En la primera, Massimiliano Di Fazio se adentra en la Italia prerromana para tratar de explicar la particular manera en que ciertas divinidades itálicas como Feronia, Marica, Mefitis o Angizia fueron absorbidas por Roma. Seguidamente, el autor se esfuerza en transmitir cómo, para estas deidades itálicas, la maternidad nunca pasó de ser una más de las múltiples facetas en que dividían su actividad. A renglón seguido, Tao Thykier Makeeff estudia la apropiación de aspectos de la maternidad biológica por parte de los alquimistas taoístas. Partiendo de la concepción de que el Taoísmo es una forma de politeísmo, se destaca cómo ciertas comunidades taoístas han venido practicando una forma de meditación que se fundamenta en la idea de que todo adepto varón tiene un útero en el cual se está desarrollando un embrión. Mediante esta particular "inversión de género" se pretende, en última instancia, revertir el proceso natural de descomposición del cuerpo humano. Carla del Zotto, por su parte, ha estudiado la generación de monstruos, dioses y héroes en distintos mitos nórdicos (como la Edda prosaica). La autora analiza cómo la mitología nórdica explica los orígenes de ciertos pueblos bien a través de personajes hermafroditas, bien a través de uniones de linajes diversos en los cuales la función generadora es llevada a cabo, indistintamente, por personajes masculinos o femeninos. Esta circunstancia no excluye, en ningún caso, la relevancia de las divinidades femeninas nórdicas en muchos otros mitos. Seguidamente, Filippo Gradi analiza la maternidad en el mito japonés a través del Kojiki, el libro histórico más antiguo que se conserva sobre la historia de Japón. Para comprobar cómo se ha construido el discurso ideológico del poder patriarcal dentro del sintoísmo, el autor contrapone la figura de la diosa Amaterasu - asociada a la pureza, en parte por haber nacido directamente de su padre, sin mediación femenina - con la de Izanami, deidad cuyos actos "impuros" no solo traen la desgracia a su marido, sino también a algunos de sus descendientes. El bloque de contenidos se cierra con el estudio de Maria Teresa 
Rondinella acerca de la figura de los gemelos en las religiones politeístas. A través de un análisis comparado, la autora pretende mostrar cómo, lejos de asociar automáticamente los partos múltiples con valores considerados positivos como la fertilidad, en la mayor parte de las ocasiones esta clase de alumbramientos son mirados con suspicacia al considerarse más propios de animales. En última instancia, se puede afirmar que lo que la sociedad se encuentra juzgando es la conducta moral de esa madre.

El último bloque de contenidos, titulado "Giving Life, Facing Death: Maternal Love, Maternal Pride, and Maternal Dangers", se estructura en torno a cuatro trabajos. En el primero de ellos, Pascale Engelmajer (re)interpreta la maternidad budista. Se parte de una crítica a la visión tradicional de Mahāmāyā, la madre de Buda, con el objetivo de tratar de atisbar su verdadero grado de agencia. De este modo, poniendo el foco en la elección personal de esta mujer de convertirse en la madre del Buda, se nos muestra cómo la maternidad, lejos de ser (necesariamente) un destino obligado para las mujeres budistas, puede constituir también una especie de "opción espiritual". Seguidamente, Catherine Whittaker estudia la relación entre el simbolismo de la serpiente y el culto a la Diosa Madre en Milpa Alta (Méjico). A través de un estudio de campo de quince meses de duración, la autora nos muestra no solo una sociedad que presenta múltiples hibridaciones culturales (aztecas e hispanas) sino que también, de alguna manera, ha integrado un animal típico de su entorno geográfico (la serpiente) dentro de una construcción específica sobre la maternidad. De esta manera, las serpientes pueden constituir, o bien un augurio positivo, o bien un peligro a evitar. A continuación, Elisa Groff analiza la salud de la madre y del recién nacido en dos textos de la antigüedad, las Antiquitates Rerum Divinarum de Varrón y el De Medicina de Celso. Haciendo uso de algunos fragmentos de la obra "anticuaria" del primero, Groff afirma que, en la Roma republicana, el discurso religioso primaba la salud del feto, primero, y del niño/a, después, sobre la de la madre. En la producción de Celso podemos ver, además, cómo para los médicos de la antigüedad la maternidad no es más que una condición médica; así, la figura de la madre - a excepción de todos los aspectos relativos a la supervivencia del feto - resulta, por tanto, casi ignorada por completo. El último trabajo de esta sección es el texto de Anita Crispino y Massimo Cultraro sobre las representaciones y las polisemias de la figura femenina en algunas necrópolis de la Sicilia protohistórica (ss. XIII-VIII a.C.) como Monte Finocchito, Monte Alveria-Noto Antica o Pantalica. Estos estudiosos afirman cómo con anterioridad a la colonización griega estas necrópolis sicilianas albergaban (en algunas de sus tumbas) a mujeres fallecidas con sus hijos muertos prematuramente. La riqueza de los ajuares de estas mujeres habla en favor de la relevancia y la alta estima social que las mismas poseían en el seno de sus respectivas sociedades. 
Quisiera afirmar, para concluir, que este volumen presenta una miscelánea de estudios muy interesantes desde un punto de vista metodológico, pues tanto su amplia perspectiva cronológica como la variedad de culturas que aborda contribuyen a enriquecer nuestro conocimiento de un fenómeno, el de la maternidad, todavía poco conocido en comparación con otros temas de estudio. El análisis comparado de realidades diversas que se plantea en este libro contribuye, sin ningún género de duda, a enriquecer las perspectivas analíticas en un mundo investigador cada vez más especializado. Sin embargo, temo que la excesiva diversidad de temáticas abordadas en el volumen, así como los múltiples idiomas en los que se encuentran escritas las contribuciones, restará lectores a un libro que, no obstante, será reconocido como un importante trabajo de referencia sobre la maternidad durante los próximos años. 